\title{
"Você Sabia? O Direito te Desafia!": Relato de Caso do Uso de Jogo de Tabuleiro com Cartas para Demonstrar a Alunos de Ensino Médio o Quanto o Direito pode ser Instigante.
}

\author{
Raquel von Hohendorff ${ }^{1}$, Wilson Engelmann'1, Afonso Vinício Kirschner Fröhlich², \\ Isabelle de Cássia Mendonça ${ }^{2}$ \\ ${ }^{1}$ Programa de Pós-Graduação em Direito Público - Mestrado e Doutorado (UNISINOS) \\ Avenida Unisinos - 950- 93022-750 - São Leopoldo - RS - Brazil \\ ${ }^{2}$ Faculdade de Direito- Universidade do Vale do Rio dos Sinos (UNISINOS) \\ Avenida Unisinos - 950- 93022-750 - São Leopoldo - RS - Brazil \\ \{rhohendorff, wengelmann\} @unisinos.br, afonsovkf@gmail.com, \\ isabelledecassiamendonca@hotmail.com
}

\begin{abstract}
This article presents the gamification methodology applied to Law. The experience was carried out with high school students, at an event at UNISINOS and, afterwards, it was adapted for Law Graduation. The methodology addresses, from a systemic-constructivist theoretical framework, Luhmann (2007), the communication between the Education System and the Legal Education Subsystem, in addition to the Social System and the Political System, placing the student in real or fictitious situations that require a legal solution. The teaching-learning-assessment strategy proved to be challenging, bringing to the area, still very conservative, a methodology capable of simulating social situations common to legal professionals.
\end{abstract}

Resumo. Este artigo apresenta a metodologia da gamificação aplicada ao Direito. A experiência foi executada com alunos do Ensino Médio, em evento na UNISINOS, e, após, foi adaptada para a Graduação em Direito. A metodologia aborda, a partir do referencial teórico sistêmico-construtivista, Luhmann (2007), a comunicação entre o Sistema da Educação e o Subsistema da Educação Jurídica, além do Sistema Social e do Sistema Político, colocando o aluno em situações reais ou fictícias que exigem uma solução jurídica. A estratégia de ensino-aprendizagem-avaliação se mostrou desafiadora, trazendo à área, ainda muito conservadora, uma metodologia capaz de simular situações sociais comuns aos profissionais do Direito.

\section{Introdução}

Um dos grandes desafios da atualidade é como atrair estudantes de Ensino Médio para algum curso de graduação. Como encantá-los? Como motivá-los a escolher um determinado curso em uma Universidade específica?

Por conta deste desafio, há alguns anos, a UNISINOS - Universidade do Vale do Rio dos Sinos tem planejado e realizado um grande evento chamado de "UNISINOS CONECTA". Este evento ocorre no campus da Universidade em São Leopoldo e todas as escolas de Ensino Médio da região metropolitana de Porto Alegre são convidadas a participar, reunindo em média mais de 5.000 alunos. 
No ano de 2019, a coordenação do Curso de Ciências Jurídicas e Sociais foi desafiada pelos organizadores do evento a criar um jogo que pudesse atrair e demonstrar aos alunos de Ensino Médio o quanto o Direito está presente em suas vidas e ao mesmo tempo, provocá-los a pensarem temas atuais que envolvem a sociedade e o Direito. Assim, uma professora do curso foi chamada pela coordenação com o intuito de elaborar um jogo. O texto que segue relata esta experiência, demonstrando também o conceito e as razões da escolha das estratégias metodológicas da gamificação e da aprendizagem. Ainda, ocorre a descrição de como esta ação foi desenvolvida, apresentando o modelo de cartas e tabuleiro desenvolvidos, mencionando também os desafios da aplicação de uma metodologia um tanto quanto diferente em uma área do conhecimento ainda muito tradicional.

A elaboração deste artigo utiliza a perspectiva metodológica sistêmicoconstrutivista, considerando a realidade como uma construção de um observador. Tratase de uma estratégia autopoiética de reflexão jurídica sobre as próprias condições de produção de sentido, bem como as possibilidades de compreensão das múltiplas dinâmicas comunicativas diferenciadas em um ambiente complexo, consoante Luhmann (2007).

\section{Referencial Teórico}

As chamadas metodologias ativas de ensino, conforme Diesel, Baldez e Martins (2019), apesar de estarem em ampla evidência na atualidade, têm sido desenvolvidas e elaboradas em nossa educação desde a década de 1930, com o movimento da Escola Nova.

Este método ativo, ao contrário dos passivos tradicionais, parte da aplicação de teorias e práticas onde o protagonista é o educando. Para tanto, utiliza-se a ideia de aplicação dos princípios da problematização da realidade, pensamento sistêmico, reflexão de forma a potencializar o protagonismo dos alunos na construção do conhecimento, na interpretação e na intervenção da realidade - nesses termos, Diesel, Baldez e Martins (2019).

Para a definição da metodologia da gamificação, utiliza-se a perspectiva de Alves et al. (2014, p.76) ao mencionar que ela "[...] se constitui na utilização da mecânica dos games em cenários non games, criando espaços de aprendizagem mediados pelo desafio, pelo prazer e entretenimento". Ademais, insta destacar que a área de educação é atualmente uma das maiores consumidoras de produtos gamificados, uma vez que auxilia no processo de aprendizagem de maneira mais lúdica e aumenta a motivação dos participantes, consoante afirma Bem (2014). Importante observar, ainda, que o ato de aprender é uma consequência de situações externas e apenas irá ocorrer quando existir, pelo sujeito, uma assimilação ativa. Logo, é atribuída a responsabilidade do processo de aprendizagem ao indivíduo que recebe este conhecimento. Nesse sentido, elucida Piaget (1972, p. 11): “Toda a ênfase é colocada na atividade do próprio sujeito, e penso que sem essa atividade não há possível didática ou pedagogia que transforme significativamente o sujeito". Assim, de acordo com Maturana e Varela (2002), a cognição é a ação efetiva, é o processo de acoplamento estrutural no qual faz emergir as interações com o mundo interno e externo.

Desta forma, a ideia foi usar o mundo real, trazendo situações fáticas atuais que permeiam os liames jurídicos - mesmo que não pareça ser o caso para os estudantes -, 
de forma a demonstrar que o Direito está sempre nos desafiando. Conforme Morin (2002) e Schlemmer (2014) pode-se compreender que o uso de jogos ou a gamificação auxilia não apenas no engajamento, mas também na aprendizagem dos estudantes. Ademais, favorece a comunicação entre a Universidade e a sociedade (aqui representada pelas escolas) - conforme Freire (2000) -, de forma que os alunos conseguem visualizar pontes que unem os diferentes elos desta cadeia.

De certa maneira, o que se buscou com a criação do jogo e posterior aplicação, foi uma educação em posição libertadora, de forma que os participantes se sintam sujeitos de seu pensar. Revisitam-se os ensinamentos de um dos grandes mestres do ensino de Direito, Luís Alberto Warat (1985), que, em sala de aula, pretendia ter cúmplices, e não discípulos ou alunos. Nessa distinção, reside um fundamento central de seu pensamento educacional para o Direito: a sala de aula não é local para submissão ou repetição de discursos, mas para que os colaboradores retomem os vínculos do saber com a vida como única arma afetivo-intelectiva contra a crise de civilização que marca o segundo milênio da cultura cristã ocidental. Ele, de diferentes maneiras, procurava sempre ter a preocupação de expor a crítica à vontade de verdade, transformando o espaço de uma sala de aula em um circo mágico. Logo, esse encanto pelo ensinar e aprender poderá ser despertado pela metodologia da gamificação.

\section{Metodologia}

O jogo "Você sabia? O Direito te desafia!" é composto de um tabuleiro com cartas, uma espécie de mistura de um Quiz e de outras situações. O jogo é realizado por até 4 jogadores (ou por grupos) e usam-se peões montados com lego e um dado. O tabuleiro (conforme demonstrado na figura 1) é marcado com diferentes cores e o jogador, ao deslocar seu peão, cairá em uma das posições do tabuleiro, devendo retirar uma carta correspondente à cor da sua posição. Existem algumas posições onde nada ocorre com o jogador e também uma posição marcada pela deusa Themis, na qual o jogador escolhe andar duas casas ou deixar algum outro participante sem jogar. Ainda, existe uma casa marcada por sinais de pontos de exclamação, que significam "fique duas rodadas sem jogar".

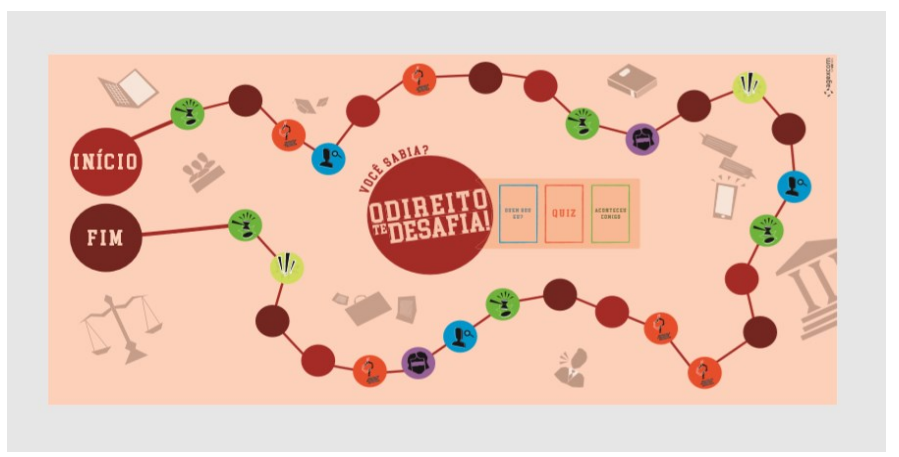

Figura 1. Tabuleiro do jogo "Você Sabia? O Direito te desafia!".

As posições marcadas em azul, verde e laranja, significam que o jogador deve retirar uma carta da respectiva cor. O jogo contém 10 cartas de cada modalidade. As cartas azuis (figura 2) são as que contém perguntas sobre "Quem sou eu?" e dispõem sobre as diferentes possibilidades de atuação dos profissionais graduados em Direito como, por exemplo, Promotor de Justiça, Advogado, Professor/Pesquisador, Juiz. Considerando o público alvo do jogo (alunos de final do Ensino Médio), nessas cartas 
existem três alternativas de respostas. Ao acertar, o participante avança duas posições. Caso não acerte, retrocede duas posições no tabuleiro. Sempre que o jogador, ao mover seu peão, parar em um local já ocupado, deverá ou avançar uma posição, ou, em caso de resposta incorreta, retroceder uma.
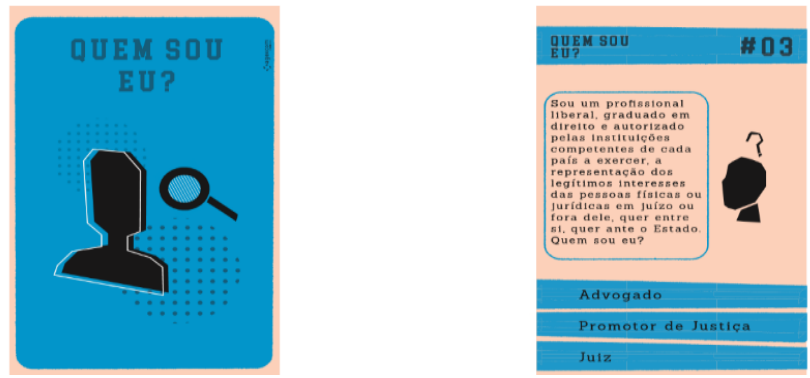

Figura 2. Cartas "Quem sou eu?”.

As cartas laranjas (figura 3), são as "QUIZ", nas quais é relatada uma situação da atualidade, como por exemplo: hoje em dia muitas provas processuais são realizadas através de comprovação de postagens em redes sociais, e o jogador deve responder verdadeiro ou falso para esta afirmação. Aqui o critério de avanço e retrocesso é o mesmo aplicado no caso das cartas azuis (“Quem sou eu?”).
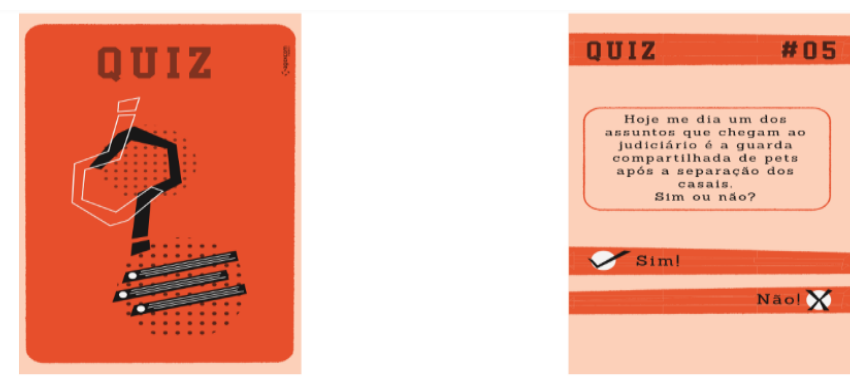

Figura 3. Cartas "QUIZ".

As cartas verdes, de outra forma, são situações que ocorreram com o jogador, como uma espécie de "jogo da vida", sendo que 5 cartas representam acontecimentos positivos e indicam que o jogador deve avançar, e 5 demarcam ocorrências negativas e indicam retrocesso para o peão do jogador. Um exemplo utilizado é que ao ser demitido, o jogador não recebeu corretamente suas verbas rescisórias - causa de mais de $50 \%$ das reclamações trabalhista no país - e por isso deverá ficar uma rodada sem jogar, pois precisará de tempo para consultar um advogado e constituí-lo como seu procurador. A figura 4 apresenta uma amostra do modelo de carta verde, "Aconteceu comigo" e verifica-se que estas sempre mencionam o que vai acontecer com o jogador.
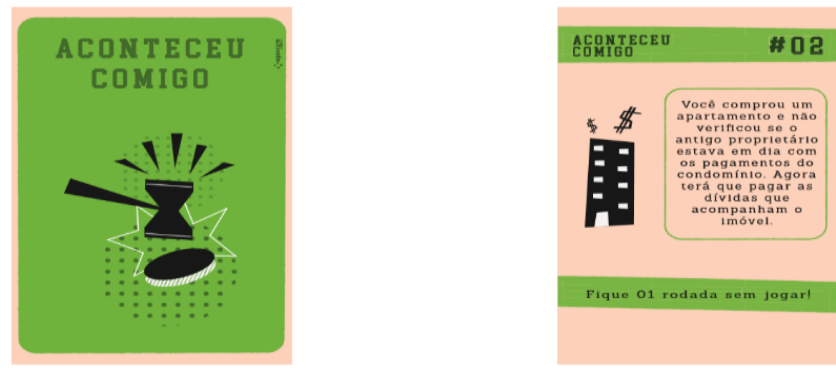

Figura 4. Cartas "Aconteceu comigo". 
Desta forma, o jogo vai se desenrolando com o movimento dos peões no tabuleiro e o ganhador é quem atinge primeiramente o final.

No evento "UNISINOS CONECTA", o jogo foi desenvolvido ao longo de todo o dia, com cerca de 500 participantes, e sua aplicação foi realizada pelos professores envolvidos e por alunos monitores, o que facilitou em muito a integração com os jovens estudantes de Ensino Médio (figura 5). A experiência, segundo os monitores do jogo de tabuleiro, foi extremamente inovadora e despertou a curiosidade não apenas do públicoalvo, mas de todos que estavam no evento, isso porque até mesmo alunos de outros cursos da graduação interessavam-se pela atividade.

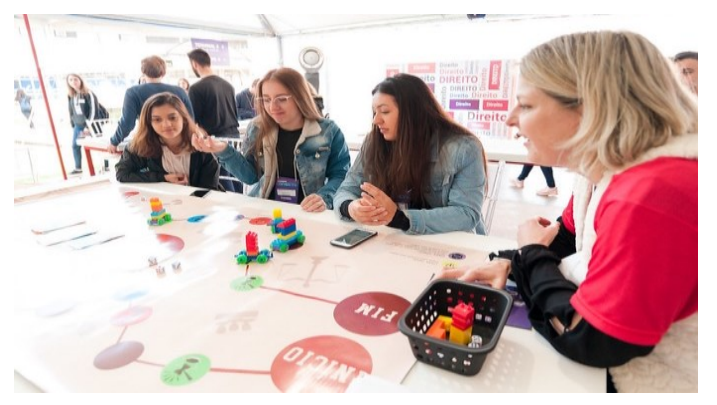

Figura 5. Alunos de Ensino Médio jogando "Você sabia? O Direito te desafia!".

Em especial, no que concerne à interação dos estudantes de Ensino Médio, foi muito satisfatório verificar o interesse e o divertimento dos alunos para com o jogo. A destacar, havia uma visível concentração e entusiasmo dos jogadores, uma vez que estes refletiam a possível resposta para as cartas que retiravam do tabuleiro - não, apenas, respondiam automaticamente ou desinteressados. Inclusive, muitos estudantes realizavam a atividade e, posteriormente, voltavam com amigos para que estes também participassem da brincadeira.

Após o uso no evento, o jogo foi utilizado em atividades acadêmicas do Curso de Direito, como "Direito Constitucional" e também em "Direito das Obrigações", quando os alunos das disciplinas desenvolveram as cartas e depois jogaram. Nesse ínterim, mais de 60 alunos envolveram-se com a elaboração e a aplicação da atividade. Em 2020/1, por conta da pandemia, o jogo está sendo adaptado para uso online, e os alunos da atividade acadêmica de "Direito do Trabalho 1", que correspondem a quantidade de 56 alunos, desenvolveram as cartas, conforme figura 6.
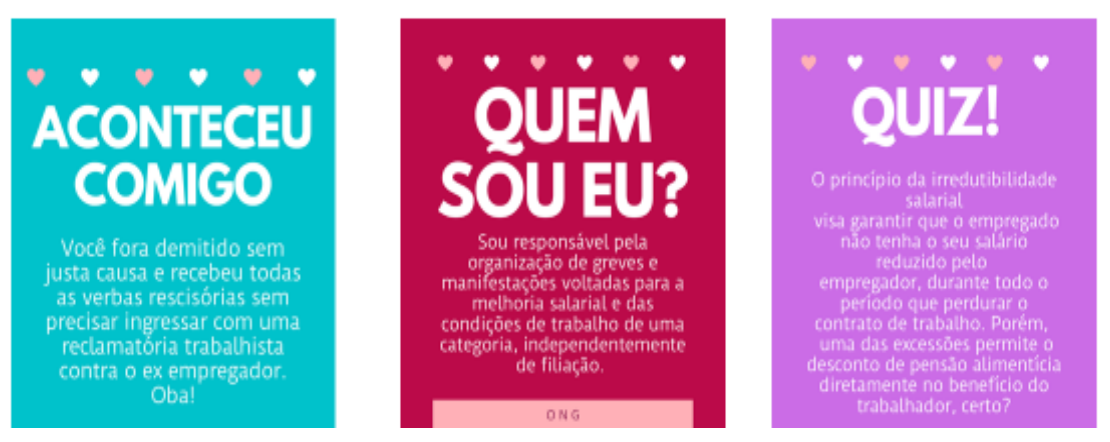

Figura 6. Cartas elaboradas pelos alunos da atividade acadêmica de "Direito do Trabalho 1". 
A metodologia permitiu a comunicação entre o Sistema da Educação e o Subsistema da Educação Jurídica, além do Sistema Social e do Sistema Político, colocando o aluno em situações reais ou fictícias que exigem uma solução jurídica. As experiências tanto com alunos de Ensino Médio quanto com graduandos de Direito, nas mais variadas atividades acadêmicas, foram muito satisfatórias e demonstraram uma boa aceitação da metodologia. A ideia é seguir desenvolvendo e adaptando o jogo para o meio virtual e para outras atividades, sempre pensando no envolvimento dos diferentes atores, de forma a propiciar uma aprendizagem menos formal e rígida, mas bem mais adaptada à realidade, bem como um aprender fazendo e ensinando. Este raciocínio sustenta que diversas são as metodologias que visam a ressignificar os modelos educacionais, e todas dependem, fundamentalmente, da boa vontade dos educadores, mas, em maior potencial, do engajamento dos estudantes, conforme Martins et al. (2019).

\section{Considerações Finais}

A experiência vivenciada com a criação e aplicação do jogo foi enriquecedora e muito agregou à experiência de todos os atores envolvidos no projeto. Percebeu-se que sim, é possível utilizar novas formas de ensinar, mesmo em áreas tão formais e normalmente aprisionados em suas próprias metodologias e tradições como o Direito. Nesse ínterim, a aplicação do método da gamificação, aqui utilizada, não se trata de uma tecnologia educacional e sim de um recurso, que pode ser adaptado às diversas atividades acadêmicas. Restou demonstrado que a utilização de jogos trata-se de uma forma diferenciada de abordar certos conteúdos e de envolver os alunos, que passam a atuar como protagonistas na construção do conhecimento.

No entanto, é importante observar que há restrições ou limitações da experiência metodológica no que se refere à inclusão. Isso porque, a exemplificar, um aluno deficiente visual precisaria ser auxiliado durante a aplicação do jogo de tabuleiro com cartas. Logo, um alerta para melhor aprimoramento da atividade, com o propósito de ser acessível a todos aqueles que desejarem usufruir desta metodologia de aprendizagem.

Percebeu-se também a resistência de alguns professores, mais tradicionais da área do Direito, com a aplicação de uma ferramenta como esta. A situação de desacomodar, de exigir um maior envolvimento e planejamento do que apenas uma aula expositiva e dialogada, para professores do Direito, pode ser ameaçadora e desestabilizadora - fugindo, portanto, das aulas convencionais.

Os alunos de pronto aceitaram a ideia e envolveram-se com muita dedicação para a elaboração da atividade, tanto nas aulas presenciais, quanto nas atividades assíncronas de 2020/1, sustentando, assim, a necessidade de remodelar a aprendizagem, uma vez que o sujeito pós-moderno anseia por um ensino diferenciado dos habituais e antiquados modos de estudo.

Portanto, deve-se perder o receio de se utilizar metodologias que não são aquelas tradicionalmente usadas no campo do Direito. Voos metodológicos são necessários para que a Ciência do Direito supere seu anacronismo frente às demais ciências, conforme Gustin et al. (2012). A Universidade detém enorme papel educativo na formação dos cidadãos, pois não prepara apenas novos profissionais, mas sim gerações nas mãos das quais está o destino e a condução de nosso país e da nossa sociedade. As faculdades de Ciências Jurídicas e Sociais devem formar pensadores e pesquisadores capazes de 
desvelar sentido e questionar autenticamente o que se faz com o Direito na sociedade, preparados para atuar em um mundo complexo, e para tanto, precisam utilizar práticas de ensino diferenciadas. Pensar o Direito a partir de uma perspectiva menos formalista e da necessidade de superação de um ensino excessivamente dogmático exige uma reflexão sobre a formação de habilidades e competências; bem como implica na prevalência do desenvolvimento do raciocínio jurídico sobre fatos reais.

\section{Referências}

Alves, L. R. et al. (2014) "Gamificação: diálogos com a educação". In: Fadel, Luciane Maria et al. (Org.). Gamificação na educação. São Paulo: Pimenta Cultural [e-book], http://www.pgcl.uenf.br/arquivos/gamificacao_na_educacao_011120181605.pdf.

Acesso em: 11 jun. 2020.

Bem, R. F. S. (2014) "Projeto Ludus: uma metodologia gamificada de gerenciamento de projetos". Dissertação de Mestrado em Design - Departamento de Design, Universidade Federal de Pernambuco, Recife, $73 \mathrm{f}$.

Diesel, A.; Baldez, A. L. S.; Martin, S. N. (2019) "Os princípios das metodologias ativas de ensino: uma abordagem teórica”. Revista Thema, [S.1.], v. 14, n. 1, p. 268288, http://periodicos.ifsul.edu.br/index.php/thema/article/view/404. Acesso em: 11 jun. 2020.

Freire, P. (2000) "Pedagogia da Indignação: cartas pedagógicas e outros escritos". São Paulo: Editora UNESP.

Gustin, M. B. S.; Lara, M. A.; Corrêa da Costa, M. B. L. (2012) "Pesquisa Quantitativa na produção de conhecimento jurídico". Revista da Faculdade de Direito da UFMG, Belo Horizonte, n. 60, p. 291-316, jan./ jun. 2012, p. 294, http://www.direito.ufmg.br/revista/index.php/ revista/article/view/186. Acessoem: 11 jun. 2020.

Luhmann, N. (2007) "La sociedad de la sociedad”. México: Herder.

Martins, D. S. et al. (2019) "LudoEscola: a Gamificação como Ferramenta de Transformação do Espaço Escolar". In: Anais do IV Congresso de Tecnologias da Educação.

Maturana, H. R.; Varela, F. J. G. (2002) “A árvore do conhecimento: as bases biológicas da compreensão humana". São Paulo: Palas Athena.

Morin, E. (2002) “Os sete saberes necessários à educação do futuro”. 5. ed. São Paulo: Cortez; Brasília: UNESCO.

Piaget, J. (1972) "Desenvolvimento e aprendizagem". Traduzido por Paulo Francisco Slomp. In: LAVATTELLY, C. S.; STENDLER, F. Reading in child behavior and development. New York: Hartcourt Brace Jonovich, p. 7-19.

Schlemmer, E. (2014) "Gamificação em espaços de convivência híbridos e multimodais: design e cognição em discussão". Revista da FAEEBA - Educação e Contemporaneidade, Salvador, v. 23, n. 42, p. 73-89, jul/dez.

Warat, L. A. (1985) "A ciência jurídica e seus dois maridos". 2. ed. Santa Cruz do Sul: EDUNISC. 